University of Wollongong

Research Online

Faculty of Engineering and Information

Faculty of Engineering and Information

Sciences - Papers: Part A

Sciences

2016

\title{
Wearable vibrotactile biofeedback device allowing identification of different floor conditions for lower-limb amputees
}

\author{
Anson Wan \\ The Hong Kong Polytechnic University \\ Duo Wong \\ The Hong Kong Polytechnic University \\ Christina Ma \\ The Hong Kong Polytechnic University \\ Ming Zhang \\ The Hong Kong Polytechnic University \\ Winson Lee \\ University of Wollongong, ccwlee@uow.edu.au
}

Follow this and additional works at: https://ro.uow.edu.au/eispapers

Part of the Engineering Commons, and the Science and Technology Studies Commons

Research Online is the open access institutional repository for the University of Wollongong. For further information contact the UOW Library: research-pubs@uow.edu.au 


\section{Wearable vibrotactile biofeedback device allowing identification of different floor conditions for lower-limb amputees}

\section{Abstract \\ Objective}

To evaluate a newly developed biofeedback device enabling lower-limb amputees to identify various floor conditions.

\section{Design}

Self-control with repeated measures (with and without the biofeedback device) within the amputee group, and group control comparing between amputee and nonamputee groups.

\section{Setting}

University locomotion laboratory.

\section{Participants}

Five lower-limb amputees and 8 nonamputees $(\mathrm{N}=13)$.

\section{Interventions}

A wearable biofeedback device, which identified different floor conditions by analyzing the force patterns under the prosthetic feet and provided vibration cues in response to different floor conditions, was provided to the amputees.

\section{Main Outcome Measures}

The subjects stepped on a foam platform concealing a small object or no object at 1 of the 4 locations of the foot sole. Subjects were asked whether there was a small object under their feet and the location of the object if it existed. The test was repeated with 4 different object types and 4 object locations. The success rate of floor identification was evaluated.

\section{Results}

Without the biofeedback device, nonamputee subjects (76.56\%) identified floor conditions better than amputees $(22.5 \%)$ significantly $(P<.001)$. On using the biofeedback device, the amputees significantly improved $(P<.01)$ their success rate showing no significant difference $(P=.746)$ compared with the nonamputees. No significant differences were found among object types $(P=.689)$.

\section{Conclusions}

Amputees performed significantly worse than nonamputees in recognizing the different floor conditions used in this experiment. With the biofeedback device, amputees significantly improved their abilities in identifying different floor conditions. Future attempts could configure the device to allow it to provide warning signals in response to fall-inducing conditions.

\section{Keywords}

conditions, lower-limb, different, identification, allowing, device, floor, biofeedback, wearable, vibrotactle, amputees

\section{Disciplines}

Engineering | Science and Technology Studies 


\section{Publication Details}

Wan, A. H., Wong, D. W., Ma, C. Z., Zhang, M., Lee, W. C. et al (2016). Wearable vibrotactile biofeedback device allowing identification of different floor conditions for lower-limb amputees. Archives of Physical Medicine and Rehabilitation, 97 (7), 1210-1213.

This journal article is available at Research Online: https://ro.uow.edu.au/eispapers/6697 


\section{1. Introduction}

Plantar mechanoreceptors provide sensory information to the brain about the foot loading [1], triggering appropriate muscular actions to maintain balance. Postural imbalance could be resulted when the plantar sensation was reduced temporarily by anesthetization [2]. Lower-limb amputees have complete loss of plantar sensation, which may explain the reported incidence [3] of over half of the amputees having fall experience. A number of studies supported that augmented feedback of foot loading and body motion improved balance in non-amputee populations [4]. However, there were few applications in lower-limb amputees.

It was reported that dynamic postural control of amputees was improved by providing real-time device reduced gait asymmetry by providing instant auditory feedback when the difference in stance time between both limbs exceeded a threshold [6]. They were used as indoor training devices only, as visual and auditory feedbacks interfere tasks of seeing and hearing in daily life.

Haptic feedback and electrical stimulation at the skin would not directly interfere with visual and auditory sensation. Subsensory electrical stimulation delivered intermittently at the quadriceps was found to improve balance of trans-tibial amputees during quite standing [5]. A few attempts were also made to generate vibratory feedback to the thigh as long as there were force applications

21 against the prosthetic foot $[7,8]$. However, frequent haptic and electrical stimuli irrespective of the types of terrains might hinder the awareness on adverse floor conditions. Adverse floor conditions 
23 challenged amputees' postural balance [9]. Impairment to detect such conditions would induce 24 falls [3].

In this study, a wearable haptic biofeedback device was developed which provided feedback only when changes in floor conditions were detected. Assessment was made to evaluate if the device can enhance the ability of amputees to identify various floor conditions via providing different vibration patterns. It provided insight to the development of biofeedback device providing warning alarm only under adverse floor conditions.

\section{Experiment description}

Subjects

Five unilateral amputees (age: $56.20 \pm 6.76 \mathrm{yr}$; height: $170.50 \pm 4.60 \mathrm{~cm}$; weight: $76.50 \pm 2.73 \mathrm{~kg}$ ) and eight healthy non-amputees (age: $41.75 \pm 19.00 y r$; height: $169.38 \pm 5.94 \mathrm{~cm}$; weight: $72.71 \pm$

$4.86 \mathrm{~kg}$ ) participated in this study. The amputees were independent walkers who had received amputations ( 2 transfemoral and 3 transtibial) over 2 years ago. All subjects were recruited from The Hong Kong Polytechnic University.

Floor conditions

One small object was concealed under a foam platform $(494.8 \mathrm{~mm} \times 380 \mathrm{~mm} \times 25.4 \mathrm{~mm}$,

42 cube $\left(25.4 \mathrm{~mm} \times 25.4 \mathrm{~mm} \times 25.4 \mathrm{~mm}, 0.644 \mathrm{mNmm}^{-3}\right)$ or a large-foam-cube $(50.8 \mathrm{~mm} \times 50.8 \mathrm{~mm} \times$

$4325.4 \mathrm{~mm}, 0.969 \mathrm{mNmm}^{-3}$ ). When subjects stepped on the shoeprint marked on the foam platform, 
44 one of the objects or no object would be located under the foot sole in one of the positions of

45 anteromedial, anterolateral, posteromedial and posterolateral regions (Figure 1A).

\section{Biofeedback device}

The device, with total weight of 166 grams, included a Plantar Force Acquisition Unit (PFAU) and

49 a Feedback Unit (FU). The PFAU consisted of 4 thin-film force sensors (A301, Tekscan, USA), a 50 microcontroller (ATMEGA328P), and a Bluetooth transmitter (HC-05, HC information Tech. Co., Ltd, 51 China) which wirelessly transmitted control signals to the FU. The FU consisted of a Bluetooth 52 receiver and a microcontroller which activated 4 vibrators (1027, Xiongying electronics Co., Ltd, 53 China). The force sensors were placed under the prosthetic foot and the vibrators were attached to 54 the hand surface detailed in Figure $1 \mathrm{~B}$ and $1 \mathrm{C}$.

Different locations of the test object produced different plantar force patterns, making the device capable of recognizing 1) whether there was an object under the foot and 2) the location of

57 the object, if any. The microcontroller analyzed the force patterns corresponding to the location of 58 the objects and sent control signals to the FU. One of the 4 vibrators was activated to provide $1 \mathrm{G}$ 59 haptic stimulus in response to the 4 locations of the object. No vibration was given in an unloaded condition and during stepping on the foam platform with no-object condition. The force acquisition

61 rate and the signal transmission time were $60 \mathrm{~Hz}$ and $0.670 \mathrm{~ms}$, respectively. 
The prosthetic limbs of the amputees and the left legs of non-amputees were tested. All subjects wore the same shoe model. Calibration of the biofeedback device was performed for each subject by recording the force pattern upon stepping on each floor condition. The subjects were given 15 minutes before the tests to accustom to the biofeedback in every floor condition. The subjects stood behind the foam platform. They stepped on the shoeprints above the platform with their tested side, followed by the progression of the opposite limb. Within 5 seconds, the subjects answered whether there was an object under the feet and the location of the object if it existed. A

71 total of 160 trials in randomized order ((3-test-objects +1 -no-object) $\times$ 4-locations $\times 5$-times $\times 2$ -

72 device-on/off conditions) were conducted for amputees. No biofeedback was used in non73 amputees.

\subsection{Statistic analysis}

The successful rates of identifying the locations of each test object were computed. A statistical programme SPSS v.20.0 (IBM Corp., NY) was used for analysis. Paired-sampe T test was conducted

78 to study if the differences in successful rates in amputees between with and without the biofeedback device were significant. Independent $T$ test was used to study if the difference 80 between amputees (with and without the biofeedback device) and non-amputees was significant.

81 One-way ANOVA was used to study if the difference in successful rates among object types was 82 significant. The level of significance was set at 0.05 . 
Without the biofeedback device, the amputees had significantly lower successful rates than non-amputees in each of the 4 object types $(p<0.003)$ and in aggregate $(22.50 \%$ vs $76.56 \%$, $p<0.001)$. Turning on the biofeedback device significantly improved $(p<0.01)$ the successful rate of amputees making them comparable (no significant difference, $p=0.746$ ) to non-amputees in each object type and in aggregate. No significant differences were found among object types ( $p=0.689)$. Each amputee had used the biofeedback device for an accumulated time of more than 30 minutes, without any complaints of discomfort.

\section{Discussion}

Lower-limb amputees performed significantly worse than non-amputees in identifying various floor conditions. When they used the biofeedback device, they remarkably improved their test performance. A $100 \%$ successful rate was not achieved in both amputee and non-amputee subjects. This might be explained by the small rocking motions of the foot relative to the foam platform during the 5-second sensing period, which made the floor identification more difficult.

One distinctive feature of this biofeedback device was that haptic stimuli were generated only when the support surface was no longer flat. This may address the shortcoming that provision of feedback for every step might lower users' awareness to changes in environmental and physical conditions.

Walking on different terrains or with instability produces various force-time patterns [10]. Future attempts can configure the device to 1) increase the force-sensing resolution, 2) enhance the algorithm to detect various physicals and environments, and 3) provide warning feedback in response to some conditions that may impose imbalance. Investigation can be conducted on its effectiveness in fall reduction in daily living. 
109 The haptic biofeedback device could allow lower-limb amputees to sense different floor 110 conditions. This preliminary study inspired further development in biofeedback devices contributing 111 to fall prevention among lower-limb amputees.

\section{Ethical Statement}

This study was approved by the Human Subjects Ethics Sub-committee (Ref. No.: HSEARS 20131028001). Subjects fully understood the purpose and the experimental procedure and 116 consented before the tests.

\section{Acknowledgement}

The study was supported by research studentship from the Hong Kong Polytechnic University and Innovation Technology Fund (ITS/030/13) from Hong Kong SAR.

\section{References}

123 1. Watanabe, I., \& Okubo, J. (1981). The role of the plantar mechanoreceptor in equilibrium 124 control. Annals of the New York Academy of Sciences, 374(1), 855-864.

125 2. Meyer, P. F., Oddsson, L. I., \& De Luca, C. J. (2004). The role of plantar cutaneous sensation in unperturbed stance. Experimental brain research,156(4), 505-512. 
fear of falling among lower extremity amputees. Archives of physical medicine and rehabilitation, 82(8), 1031-1037.

\section{Suppliers}


152 Tekscan, Inc. e-mail: marketing@tekscan.com

153 Atmel Co. e-mail: invest@atmel.com

154 HC information Tech. Co. e-mail: sales@wavesen.com

155 Xiongying electronics Co., Ltd e-mail: $\underline{\text { ddhsz@163.com }}$

156

157 
159 Figure 1. Illustration of the experiment and the haptic biofeedback device.

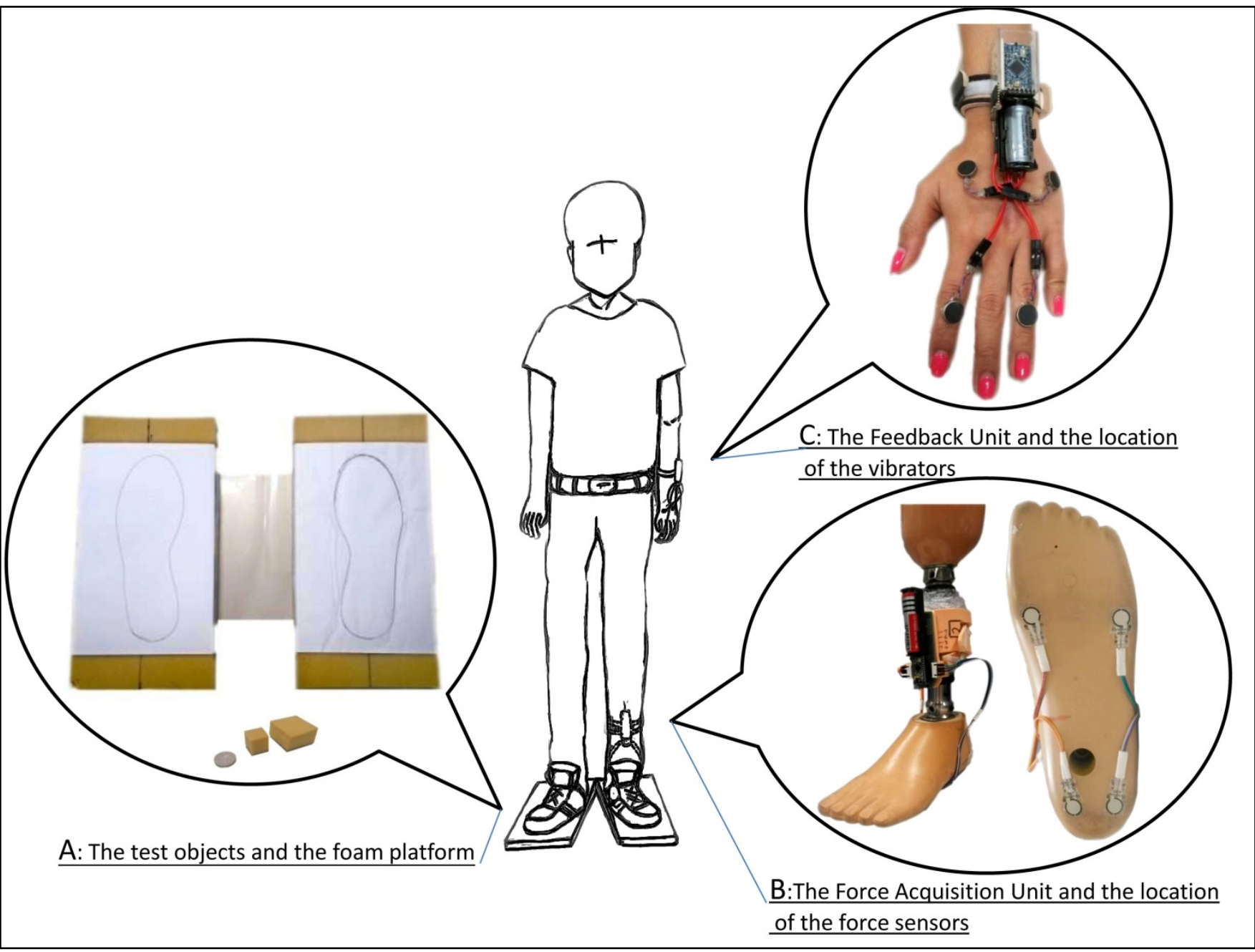

161 A: The test objects used in this study, resembling uneven terrains and small objects on the floor which may induce slip and fall when stepped on. The shoeprints on the surface of the foam platform ensured that the test object was at one of the four designated positions when stepped on.

B: Location of the four thin-film sensors (9.53mm diameter) and attachment of the force acquisition unit to the prosthetic shank.

C: The feedback unit was fastened to the wrist. Four vibrators, which were wired to the feedback unit, were attached at (1) the proximolateral and (2) proximomedial regions of dorsal hand surface, the middle phalanx of (3) index and (4) ring fingers. 
Table 1. The successful rates of floor identification among amputees and non-amputees.

\begin{tabular}{|c|c|c|c|c|}
\hline \multirow[b]{2}{*}{ Object types } & \multicolumn{2}{|l|}{$\begin{array}{l}\text { Amputees } \\
(n=5)\end{array}$} & $\begin{array}{l}\text { Non-amputees } \\
(n=8)\end{array}$ & \\
\hline & $\begin{array}{l}\text { (A) Device off } \\
{[\%](S D)}\end{array}$ & $\begin{array}{l}\text { (B) Device on } \\
{[\%](S D)}\end{array}$ & $\begin{array}{l}\text { (C) Device off } \\
{[\%](S D)}\end{array}$ & $\begin{array}{l}\text { Average (across } \\
\text { object types) }\end{array}$ \\
\hline None & $21.00(7.41)$ & $75.00(6.12)$ & $80.62(4.95)$ & $62.50(27.18)$ \\
\hline Coin & $16.00(15.16)$ & $75.00(5.00)$ & $71.25(14.82)$ & $56.94(28.90)$ \\
\hline Small foam cube & $26.00(21.03)$ & $73.00(9.74)$ & 69.37(17.81) & $58.33(26.17)$ \\
\hline Large foam cube & $27.00(18.23)$ & $79.00(12.94)$ & $85.00(15.11)$ & $67.22(29.61)$ \\
\hline $\begin{array}{l}\text { Average (across } \\
\text { subjects) }\end{array}$ & $22.50(15.60)$ & $75.50(8.56)$ & $76.56(14.88)$ & $61.25(27.70)$ \\
\hline
\end{tabular}

